\title{
Inclusão Educacional de Crianças com Deficiência Intelectual através de Estratégias Mobilizadas pelos Professores da Educação Infantil
}

\author{
Jainy Mikaely Alves Landim ${ }^{\text {; }}$ Marta Callou Barros Coutinho ${ }^{2}$; Maria do Socorro Cecílio Sobral ${ }^{3}$
}

\begin{abstract}
Resumo: Discutir sobre a inclusão educacional de crianças com deficiência intelectual no contexto escolar é de suma relevância para melhoria e qualificação do profissional docente. $\mathrm{O}$ artigo buscou identificar as bases teóricas que sustentam a inclusão educacional de crianças com deficiência intelectual, através de estratégias mobilizadas pelos professores da educação infantil. Baseou-se na reflexão de leituras de autores renomados como Barbosa e Duarte (2016), Coutinho (2013), entres outros, e do Ministério da Educação (2007), da LDB (1996) e a Política Nacional de Educação Especial (2008). Tais autores e documentos discutem a temática abordada. A pesquisa a questão da inclusão como forma de alertar para as práticas cotidianas e as situações em que há exclusão. Aborda a questão da deficiência intelectual com o intuito de caracterizá-la e discutir a respeito, bem como contextualizar a prática pedagógica com foco nas aprendizagens significativas. Os resultados levaram a crer que a prática pedagógica na atuação junto a crianças com deficiência intelectual, assim como as estratégias utilizadas no cotidiano a favor de uma aprendizagem de forma integral tem favorecido a inclusão. Ainda é um desafio, uma prática pedagógica voltada para a valorização do estudante com deficiência intelectual, como um ser participante e importante na evolução da sociedade.
\end{abstract}

Palavras-Chave: Aprendizagem. Deficiência Intelectual. Inclusão. Prática Pedagógica.

\section{Educational Inclusion of Children with Intellectual Disabilities through Strategies Mobilized by Teachers of Early Childhood Education}

\begin{abstract}
Discussing the educational inclusion of children with intellectual disabilities in the school context is of great relevance for the improvement and qualification of the teaching profession. The article sought to identify the theoretical bases that support the educational inclusion of children with intellectual disability, through strategies mobilized by teachers of early childhood education. Based on the reflection of readings by renowned authors such as Barbosa and Duarte (2016), Coutinho (2013), among others, and the Ministry of Education (2007), LDB (1996) and the National Policy on Special Education (2008) . These authors and documents discuss the subject. Research the issue of inclusion as a way of alerting to everyday practices and situations in which there is exclusion. It addresses the issue of intellectual disability with the aim of characterizing and discussing it, as well as contextualizing the pedagogical practice with a focus on meaningful learning. The results led us to believe that the pedagogical practice in the work with children with intellectual disabilities, as well as the strategies used in the daily life in favor of a full learning has favored the inclusion. It is still a challenge, a pedagogical practice aimed at valuing the student with intellectual disability, as a participant and important being in the evolution of society.
\end{abstract}

Keywords: Learning. Intellectual Disability. Inclusion. Pedagogical Practice.

\footnotetext{
${ }^{1}$ Faculdade de Ciências Humanas do Sertão Central (FACHUSC). E-mail: jainymikaely@hotmail.com;

${ }^{2}$ Faculdade de Ciências Humanas do Sertão Central (FACHUSC). E-mail: mcallou @ hotmail.com;

${ }^{3}$ Mestrado em Educação em Ciências pela Fundação de Apoio à Universidade Federal do Rio Grande do Sul, Brasil. Professora da Faculdade de Ciências Humanas do Sertão Central (FACHUSC). E-mail: socorrosobral@ bol.com.br
} 


\section{Introdução}

O artigo em questão se caracteriza como pesquisa bibliográfica acercada temática da inclusão educacional e as estratégias de aprendizagem mobilizadas pelos professores da educação infantil que atuam no atendimento a crianças com deficiência intelectual.

O estudo da temática apresentada, justifica-se por constitui-se de fundamental relevância para compreensão da prática pedagógica no atendimento das crianças com deficiência intelectual, de forma a identificar como o educador pode a partir de suas habilidades e competências e proporcionar a Educação infantil um ambiente favorável à aprendizagem significativa e a inclusão.

Com isso, o referido estudo tem como problemática discutir de que forma a prática pedagógica pode contribuir para a inclusão educacional e para a aprendizagem significativa a partir das demandas de alunos diagnosticados com deficiência intelectual? Essa reflexão proporciona maior entendimento sobre a temática, assim como contribui para ampliar os conhecimentos frente às demandas relacionadas às necessidades especiais, intensificando a discussão sobre o processo de inclusão e assim favorecer a construção de estudos posteriores.

Portanto, o trabalho tem como principal objetivo apresentar uma discussão clara e objetiva acerca da inclusão educacional de alunos diagnosticados com deficiência intelectual, com foco na prática pedagógica e na abordagem utilizada pelo educador para promover uma educação de qualidade, assim como favorecer a aprendizagem significativa para os alunos, superando as barreiras ainda existentes frente à inclusão com o intuito de coibir as diferentes formas de preconceito que se apresentam na sociedade contemporânea.

Para tanto serão discutidos resultados de pesquisas voltadas para o atendimento educacional especializado, especificamente no que se refere a deficiência intelectual, realizadas por autores como Barbosa e Duarte (2016) que abordam a questão da escolarização a partir de produções científicas; dados do Ministério da Educação (2007) que discute e norteia a prática de formação continuada de professores que atuam no atendimento educacional especializado; resultados de pesquisas com foco na construção de saberes docente direcionado a inclusão das pessoas com deficiência fundamentado por Coutinho (2013); assim como outras fontes de pesquisa, a exemplo da LDB (1996) e a Política Nacional de Educação Especial (2008).

Diante disso, o estudo em questão no seu referencial teórico foi dividido em três sessões, onde a primeira trata-se da questão da inclusão frente às demandas existentes relacionadas às 
necessidades especiais, chamando atenção também para a problemática da exclusão seja ela de forma clara ou disfarçada.

A segunda sessão aborda de forma sucinta a questão da deficiência intelectual com o intuito de caracterizá-la e discutir a respeito, como forma de aprofundar os conhecimentos em relação à temática, bem como de contribuir para promover uma educação inclusiva e significativa.

A terceira apresenta uma contextualização da prática pedagógica com foco nas aprendizagens significativas, estabelecendo as competências e habilidades profissionais que o professor precisa desempenhar no seu cotidiano, a partir de sua formação docente considerando as suas responsabilidades e as exigências relacionadas ao atendimento de crianças com necessidades especiais.

\section{Referencial Teórico}

\section{Inclusão: da inclusão a exclusão}

A temática da inclusão de pessoas com necessidades especiais traz uma série de questionamentos e situações que colocam em discussão qual a educação que vem sendo ofertada, considerando os direitos humanos, a cidadania e a igualdade no acesso aos serviços educacionais, bem como as políticas públicas que asseguram tais direitos, que dizem tratar-se de uma educação inclusiva.

Segundo as Leis de Diretrizes e Bases da Educação Nacional (LDB): Art. 58. Entendese por educação especial, para os efeitos desta Lei, a modalidade de educação escolar, oferecida preferencialmente na rede regular de ensino, para educandos portadores de necessidades especiais (BRASIL, 1996, p. 25).

Considerando a trajetória das políticas de educação inclusiva no Brasil, pode-se dizer que na prática, a maioria das instituições de ensino não dispõem de condições favoráveis para o acesso ao ensino regular, contradizendo, portanto, o que estabelece a LDB, contribuindo para a segregação escolar das pessoas com deficiência.

Essa oferta e o atendimento destinados aos alunos com deficiência intelectual, ainda se mostra como um desafio constante para as escolas, que muitas vezes não dispõem de recursos 
e instalações necessárias para o acolhimento e a educação de qualidade que visem à inclusão de estratégias e metodologias que atendam as necessidades dos alunos.

A Política Nacional de Educação Especial implementada em 2008, na perspectiva da Educação Inclusiva, propõe que esta atue de maneira articulada com o ensino comum. A Política Nacional de Educação Especial foi um marco importante e mudou a visão da educação especial no sistema de ensino brasileiro.

Desta forma, apresenta uma nova abordem, na perspectiva da educação inclusiva, complementa os estudos de alunos com deficiência com mais recursos para facilitar o acesso, permanência e participação nas turmas comuns de ensino regular, com autonomia e independência. A mesma passa a garantir o acesso de todos os alunos ao ensino regular, fomentando a formação de professores para a inclusão e melhorando o acesso físico, transporte e mobiliário. Eliminou a possibilidade de exclusão total ou parcial das turmas comuns, o estudante da Educação Especial, muitas vezes era atendido em classes especiais, com a nova Política Nacional, os alunos com deficiência serão atendidos nas salas comuns e atendidos também em salas de recursos.

Dessa maneira, a educação inclusiva sugere que as escolas tenham suas bases metodológicas pautadas nas necessidades dos alunos, em oferecer um atendimento de qualidade através de práticas que estimulem a aprendizagem e o respeito mútuo, proporcionando diversas possibilidades de desenvolvimento.

A educação inclusiva vem sendo muito discutida nas últimas décadas e se mantém sustentada por legislações e políticas públicas que propõe uma implementação e execução de ações que visem o respeito e a diversidade, onde as oportunidades sejam para todos, buscando uma sociedade igualitária, que venha a romper com a discriminação e exclusão, constantes na prática de educação inclusiva.

Sobre a educação inclusiva a Política Nacional de Educação Especial instituída em 2008 dispõe:

\begin{abstract}
A educação inclusiva constitui um paradigma educacional fundamentado na concepção de direitos humanos, que conjuga igualdade e diferença como valores indissociáveis, e que avança em relação à ideia de equidade formal ao contextualizar as circunstâncias históricas da produção da exclusão dentro e fora da escola. (BRASIL, 2008 p. 1).
\end{abstract}

Dessa maneira, identifica-se que a proposta instituída se apresenta como uma forma legal e cidadã de superação da exclusão social, propondo a garantia de acesso universal e de 
maneira que todos sejam acolhidos sem qualquer forma de discriminação, onde o ensino seja valorizado e direcionado com a perspectiva de integração e respeito às diferenças, para que esta não seja encarada como exceção, mas sim como algo construtivo, que se relaciona com o cotidiano, estimulando o respeito e a construção do conhecimento.

Neste sentido, constata-se que apesar de haverem políticas de incentivo a inclusão social e educacional, bem como os grandes avanços existentes nesse contexto, é também notória a existência de dificuldades no sistema educacional, no que se refere o acesso e a oferta dos serviços que muitas vezes não estão de acordo com as necessidades dos alunos.

Portanto, cabe considerar que apesar dos avanços existentes no campo da educação inclusiva, ainda se percebe a necessidade de políticas públicas efetivas, continuas e complementares, para que a criança com deficiência possa ser acolhida e assistida, de modo a atender as suas necessidades, isso envolve teoria, prática, formação adequada de profissionais, recursos materiais eficientes, a fim de ofertar um ensino integrado e de qualidade.

\section{Deficiência intelectual}

A deficiência intelectual trata-se de um distúrbio, relacionado ao desenvolvimento mental da criança, que ocasiona diferentes limitações, como o comprometimento de habilidades que contribuem para o nível global de inteligência.

Conforme aponta a Organização Mundial da Saúde (1993), com base na Classificação de transtornos mentais e de comportamento (CID - 10) no estabelecimento das descrições clínicas e diretrizes diagnósticas. O nível global de inteligência das pessoas com deficiência intelectual pode se dá nos aspectos cognitivos, de linguagem, motor e habilidades sociais. As barreiras interferem significativamente no funcionamento intelectual e no comportamento adaptativo.

A definição, classificação e as formas de abordagem e tratamento da deficiência intelectual adotada no Brasil é a proposta pela AAMR (American Association on Mental Retardation), hoje denominada AAIDD (American Association on Intellectual and Developmental Disabilities). Essa proposta foi divulgada em uma revisão conhecida como o Sistema 2002, que a define como incapacidade caracterizada por importantes limitações, tanto no funcionamento intelectual quanto no comportamento adaptativo (AAMR, 2006). 
Conforme destacado, esse transtorno causa desordem intelectual no desenvolvimento e acarreta prejuízos significativos tanto no nível cognitivo, quanto social e prático. De acordo com o Manual Diagnóstico e Estatístico de Transtornos Mentais, existem três critérios que caracterizam tal distúrbio:

O Déficit nas funções intelectuais, como raciocínio, resolução de problemas, planejamento, pensamentos abstratos, julgamento, aprendizado acadêmico, aprender com a experiência, confirmada tanto por avaliação clínica e individualizada, quanto por testes de inteligência padronizados. B. Os déficits no funcionamento adaptativo que resultam em incapacidade de cumprir e de desenvolver padrões socioculturais para a independência pessoal e responsabilidade social. C. Os déficits intelectuais e adaptativas tem início durante o período de desenvolvimento (DSM V, 2014,p.33 ).

Nessa direção, identifica-se que o diagnóstico de deficiência intelectual envolve esse conjunto de fatores, e se classifica de acordo com o nível de gravidade, podendo ser leve, moderada ou grave, influenciando assim no desenvolvimento e no desenvolvimento da criança.

Nesse contexto, defende-se que a educação das pessoas com deficiência, dentro do contexto das escolas regulares de ensino parte do princípio que a educação é um direito humano básico, propiciando uma sociedade que respeita a diversidade dos educandos, promovendo uma sociedade mais justa e igualitária

Na próxima sessão, discute-se a prática pedagógica de professores para a construção de aprendizagens significativas para a inclusão educacional de todo o alunado.

\section{Aprendizagem significativa: prática pedagógica}

No contexto educacional, é importante que exista uma prática pedagógica que contribua para superação da exclusão de pessoas com deficiência, assim como a implementação de um sistema integrado e inclusivo, através de uma proposta adequada, que atenda as necessidades dos alunos e que esteja nos ideais de igualdade e universalidade de direitos.

Conforme aponta Coutinho (2013) em sua pesquisa sobre a construção de saberes docentes voltados para a inclusão das pessoas com deficiência, para que se consiga trabalhar dentro de uma proposta educacional inclusiva, é importante um olhar examinador e a busca de estratégias que se dão por meio de uma prática pedagógica dinâmica, humanizadora, com um currículo que contemple a todos os aspectos da ação mediadora nas inter-relações entre o professor e alunos com e sem deficiência. 
Com isso, entende-se que na prática se faz necessário que seja ofertada condições favoráveis à aprendizagem significativa, que seja capaz de contribuir para o desenvolvimento dos alunos com deficiência intelectual, como forma de superar as desigualdades, propondo formas alternativas e eficazes no processo ensino aprendizagem, bem como da diversidade no âmbito escolar.

Conforme destaca a Lei de Diretrizes e Bases da Educação Nacional (LDB):

\begin{abstract}
Art. 59. Os sistemas de ensino assegurarão aos educandos com necessidades especiais: I - currículos, métodos, técnicas, recursos educativos e organização específicos, para atender às suas necessidades; III - professores com especialização adequada em nível médio ou superior, para atendimento especializado, bem como professores do ensino regular capacitados para a integração desses educandos nas classes comuns (BRASIL, 1996, p. 25).
\end{abstract}

Sendo assim, constata-se que o professor deve ser profissional devidamente capacitado, para conhecer e atender as necessidades de cada aluno respeitando as suas condições e diferenças, de forma que a sua prática pedagógica leve em consideração as reais necessidades dos alunos, buscando superar suas dificuldades existentes no âmbito da inclusão educacional, buscando formas de transformar essa realidade.

De acordo com o que estabelece o Ministério da Educação na perspectiva da Educação Inclusiva, com foco na pesquisa voltada para a formação de professores que atuam no atendimento especializado, conclui:

\begin{abstract}
Ensinar é um ato coletivo, no qual o professor disponibiliza a todos alunos, sem exceção, um mesmo conhecimento. Ao invés de adaptar e individualizar/ diferenciar o ensino para alguns, a escola comum precisa recriar suas práticas, mudar suas concepções, rever seu papel, sempre reconhecendo e valorizando as diferenças. As práticas escolares que permitem ao aluno aprender e ter reconhecidos e valorizados os conhecimentos que é capaz de produzir, segundo suas possibilidades, são próprias de um ensino escolar que se distingue pela diversificação de atividades. O professor, na perspectiva da educação inclusiva, não ministra um "ensino diversificado" e para alguns. Ele prepara atividades diversas para seus alunos (com e sem deficiência mental) ao trabalhar um mesmo conteúdo curricular. Essas atividades não são graduadas para atender a níveis diferentes de compreensão e estão disponíveis na sala de aula para que os alunos as escolham livremente, de acordo com seus interesses (BRASIL, 2007, p. 17).
\end{abstract}

O professor, portanto, deve adotar uma postura crítica e reflexiva, que reavalie sua prática cotidiana, que utilize estratégias inovadoras, dinâmicas e que valorize a diversidade, que estimule o respeito mútuo, a autonomia dos alunos e a aprendizagem significativa. 
Em sua pesquisa sobre deficiência intelectual e escolarização, Barbosa e Duarte (2016) afirmam que para se promover a prática inclusiva, a inclusão escolar precisa transpor as barreiras impostas às pessoas com deficiência, procedendo em uma transformação social, onde o cidadão participe ativamente, e não mais como um personagem que vive alheio à realidade.

Considerando isso, pode-se pensar em uma realidade transformada, onde haja mudanças significativas, que estimule a interação social, o afeto e o respeito pelo outro, independentemente de sua condição cognitiva, social ou econômica, promovendo a reflexão em torno da diversidade e a compreensão da inclusão educacional, contribuindo para o desenvolvimento do alunado, estimulando as suas potencialidades e a autonomia.

O ministério da Educação através do estudo referente à formação continuada para professores direcionados ao atendimento educacional especializado aponta que a adaptação ao conteúdo escolar deve ser realizada pelo próprio aluno e testemunha a sua emancipação intelectual. Essa emancipação decorre do processo de autorregulação da aprendizagem, onde o aluno assimila o novo conhecimento, de acordo com suas possibilidades de incorporá-lo ao que já conhece (BRASIL, 2007).

É imprescindível, portanto, ao professor especializado e competente entender este sentido emancipador de que se trata a adaptação intelectual, isso por que não basta planejar e propor metodologias eficazes, inclusivas e de aprendizagem, é importante também que se promova essa autonomia e independência do aluno, de modo que ele consiga construir sua própria aprendizagem com base naquilo que incorporou.

Conforme determina a Declaração de Salamanca instituída em 1994, “As escolas deveriam acomodar todas as crianças independentemente de suas condições físicas, intelectuais, sociais, emocionais, linguísticas e outras" (BRASIL, 1994, p. 3). Isso envolve prática eficiente, conhecimento e habilidades compatíveis com a demanda existente, cabendo, pois, as instituições de ensino promover ações e desenvolver estratégias compatíveis com a política de educação inclusiva, atender as necessidades dos alunos, com base nos seus direitos, contribuindo na formação de ensino de qualidade. 


\section{Metodologia}

O trabalho em questão trata-se de estudo bibliográfico, que tem como foco principal discutir a relevância da prática pedagógica no atendimento de alunos diagnosticados com deficiência intelectual, abordando os instrumentos utilizados no cotidiano institucional. Esse embasamento teórico foi constituído através de material já publicado que tratam da temática, como forma de tornar a pesquisa fundamentada e discutir acerca do assunto.

Conforme aborda Marconi e Lakatos (2010) em seu estudo sobre metodologia cientifica, a pesquisa bibliográfica "trata-se do levantamento de toda a bibliografia já publicada em forma de livros, revistas, publicações avulsas e imprensa escrita". Sua finalidade é colocar o pesquisador em contato direto com tudo aquilo que foi escrito sobre determinado assunto.

Sendo assim, a pesquisa realizada pautou-se na leitura e no fichamento de escritos de diferentes autores que produziram estudos sobe a temática inclusão educacional de alunos com deficiência intelectual.

No que se refere à abordagem a pesquisa tem natureza qualitativa, que busca aprofundarse sobre determinada temática, a fim de melhor compreendê-la, buscando identificar diferentes aspectos e contextos, a fim de descrever, explicar e entender como determinado fato ocorre a partir de aspectos teóricos e empíricos, na busca por resultados fidedignos (GERHARDT; SILVEIRA, 2009).

\section{Resultados e Discussão}

O referido estudo possibilitou compreender a importância de uma educação de qualidade, com foco nas necessidades especiais de alunos diagnosticados com deficiência intelectual, abrangendo a relevância da prática docente frente a essa temática, como forma de apresentar uma discussão clara e objetiva acerca do atendimento e da qualidade do serviço prestado.

Assim, conforme as diferentes legislações já apontadas no trabalho, identificou-se a necessidade de formação adequada para os educadores, assim como políticas públicas efetivas e inclusivas, que possam superar os ideais de preconceito ainda existentes na sociedade atual, 
que acarretam sérias consequências, sobretudo para crianças diagnosticadas com alguma necessidade especial, a exemplo da deficiência intelectual.

Assim, conforme discutido através da LDB, da Política Nacional de Educação Especial, dentre outras legislações pertinentes, tornou-se necessário e propício discutir a temática da inclusão educacional, isso por que ainda é notório na prática institucional o despreparo e a falta de recursos sejam eles físicos ou humanos para o atendimento dessa demanda, o que torna o acesso e a permanência dos alunos com necessidades especiais na escola prejudicada e até mesmo impossibilitada.

Assim propor essa discussão mostrou-se fundamental para ampliar os conhecimentos frente à temática, bem como aprofundar os estudos acerca do assunto, como forma de contribuir para coibir as diferentes manifestações de preconceito ainda existentes na sociedade e no âmbito educacional, favorecendo uma educação de qualidade, onde haja o respeito mútuo e que o ser humano seja valorizado independente de suas características físicas, sociais e econômicas, sendo considerado como um cidadão digno de direitos.

\section{Considerações Finais}

A partir do exposto pode-se dizer que a temática da inclusão teve grandes e significativos avanços, tendo como base as diferentes políticas públicas e as leis que regulamentam o atendimento educacional qualificado e especializado, a exemplo da Política Nacional de Educação Especial instituída em 2008, a qual possibilitou a ampliação do atendimento e propôs a existência de uma pratica pedagógica inclusiva.

Através da discussão apresentada no referido estudo, pode-se concluir que a prática pedagógica desempenha papel fundamental no processo ensino aprendizagem e no desenvolvimento integral da criança, considerando os resultados apontados por Coutinho (2013) e Brasil (2007) os quais enfatizam a relevância da formação e da qualidade da prática docente na perspectiva da inclusão.

Pensar a questão da deficiência intelectual também proporcionou entender quais as necessidades relacionadas, assim como de entender como o educador pode contribuir para uma prática inclusiva e na oferta de ensino de qualidade, estabelecendo parâmetros que tem como intuito regulamentar e discutir políticas públicas relacionadas ao atendimento educacional 
especializado, utilizando a Política nacional de Educação especial (2008) como importante instrumento de atuação e direcionamento no contexto institucional.

Isso se torna relevante, pois a instituição também desempenha papel fundamental, considerando a sua responsabilidade social, favorecendo o exercício da cidadania, contribuindo para uma sociedade igualitária, desenvolvendo estratégias que visem a superação do preconceito e das diferentes barreiras existentes no que se refere à inclusão, promovendo ações responsáveis e que valorizem as diferenças.

Frente a isso, pode-se dizer que o objetivo do trabalho foi desenvolvido, visto que essa discussão tornou-se relevante, ao mesmo tempo em que trouxe uma reflexão positiva e esclarecedora referente à temática da inclusão educacional de crianças diagnosticadas com deficiência intelectual, como forma de contribuir para uma educação de qualidade, com propostas inclusivas, formação qualificada por parte dos educadores, assim como recursos físicos e humanos por parte das instituições de educação infantil, de forma que possam atender as demandas relacionadas às necessidades educacionais especiais.

Portanto, a partir da reflexão apresentada, pode-se ter uma visão esclarecedora e atual frente às políticas públicas existentes, estabelecendo os avanços assim como os desafios que permeia essa prática, a fim de ampliar os conhecimentos frente à temática e contribuir para uma educação de qualidade, que visem a garantia do acesso e da permanência de crianças com necessidades educacionais especiais nas instituições de ensino regular, conforme estabelecem as diferentes legislações apresentadas.

\section{Referências}

AMERICAN ASSOCIATION ON MENTAL RETARDATION. Retardo mental: definição, classificação e sistemas de apoio. 10ed. Porto Alegre: Artmed, 2006.

BARBOSA, M.O.; DUARTE, L. N. Deficiência Intelectual e Escolarização: uma análise das produções científicas. Comunicações Piracicaba, v. 23 n. 3 Número Especial p. 351-368 2016.

BRASIL. Lei de Diretrizes e Bases da Educação Nacional, lei nº 9.394 de 20 de Dezembro de 1996.

, Ministério da Educação. Formação Continuada a Distância de Professores para o Atendimento Educacional Especializado - Deficiência Mental. SEESP / SEED / MEC Brasília/DF, 2007. 
, Política nacional de educação especial na perspectiva da educação inclusiva. Inclusão: revista da educação especial. Brasília: Secretaria de Educação Especial, v.4, n.1, p. 7-17, janjun. 2008.

COUTINHO, M. C. B.; A construção de saberes docentes para a inclusão das pessoas com deficiência: um estudo a partir dos professores do curso de Pedagogia do Sertão Pernambucano. Dissertação de Mestrado Programa de Pós-Graduação em Educação da Universidade Federal de Pernambuco. Recife, 2013.

FONSECA, J. J. S. Metodologia da pesquisa científica. Fortaleza: UEC, 2002.

GERHARDT, T.E.; SILVEIRA, D. T. Métodos de Pesquisa.Universidade Aberta do Brasil UAB/UFRGS e Curso de Graduação Tecnológica - Planejamento e Gestão para o Desenvolvimento Rural da SEAD/UFRGS, Porto Alegre: Editora da UFRGS, 2009.

GIL, A. C. Como Elaborar um Projeto de Pesquisa. 4aed. - São Paulo: Atlas, 2002.

GOMES, A. L. L.; FERNANDES, A. C.; BATISTA, C. A. M; SAlUSTIANO, D. A.; MANTOAN, M. T. E.; FIGUEIREDO, R. V. Atendimento Educacional Especializado Deficiência Mental. Brasília - DF, 2007.

LAKATOS, E. M. MARCONI, M. A. Fundamentos de Metodologia Científica. $7^{\circ}$ ed. São Paulo: Atlas, 2010.

MANUAL DIAGNÓSTICO E ESTATÍSTICO DE TRANSTORNOS MENTAIS: DSM5 - American PsychiatricAssociation. 5. ed. - Dados eletrônicos. - Porto Alegre: Artmed, 2014.

ORGANIZAÇÃO MUNDIAL DA SAÚDE. Classificação de transtornos mentais e de comportamento da CID - 10: descrições clínicas e diretrizes diagnósticas. Porto Alegre: Artes Médicas, 1993.

SEESP/MEC. Declaração de Salamanca: recomendações para a construção de uma escola inclusiva. Coordenação geral: SEESP/MEC. Brasília: Ministério da Educação, Secretaria de Educação Especial, 1994.

Como citar este artigo (Formato ABNT):

LANDIM, Jainy Mikaely Alves; COUTINHO, Marta Callou Barros; SOBRAL, Maria do Socorro Cecílio. Inclusão Educacional de Crianças com Deficiência Intelectual através de Estratégias Mobilizadas pelos Professores da Educação Infantil. Id on Line Rev.Mult. Psic., 2018, vol.12, n.42, Supl. 1, p. 611-622. ISSN: 1981-1179.

Recebido: 12/11/2018;

Aceito: $13 / 11 / 2018$ 